\title{
Additional sedative drugs to light sedation with dexmedetomidine is risk for delirium
}

\author{
M Sakuraya*, A Hirata, K Yoshida, N Kawamura, T Tsutsui \\ From ESICM LIVES 2015 \\ Berlin, Germany. 3-7 October 2015
}

\section{Introduction}

Light sedation is preferred for critical ill patients. We often use dexmedetomidine for light sedation, but sometimes additional sedative drugs(such as midazolam and propofol) is needed. Benzodiazepine is risk for delirium, but it is unclear benzodiazepine use combined with dexmedetomidine is risk for delirium.

\section{Methods}

This prospective observational study was conducted in open ICU, urban hospital(Hiroshima, Japan) between February 2013 and March 2015. Adult patients intubated within 24 hours from ICU admission and underwent light sedation with dexmedetomidine was eligible. Exclusion criteria were: age $<18$, stroke, cardiopulmonary arrest, neurosurgery, seizure, traumatic brain injury. We compared alternative sedative dug use with no additional drug. Primary outcome is delirium incidence.

\section{Results}

268 patients were eligible and 254 patients were analyzed. Median age (Q1-Q3) was 74 (66-81) years, 162 male (64\%), median APACHE II score was 19 (15-23). 89 patients were administrated additional sedative drugs (midazolam 14, propofol 80). Delirium was observed more frequently compared with dexmedetomidine alone, $41(46 \%)$ vs. $51(31 \%), \mathrm{p}=0.02$. Additional sedative drugs were associated with prolong ICU stay (5 (3-8) days vs. 3 (2-4.5) days, $\mathrm{p}<0.001)$ and decreased ventilator free days (25 (21-26) days vs. 26 (26-27) days, $\mathrm{p}<0.001)$.

\section{Conclusions}

Additional sedative drugs to light sedation with dexmedetomidine might be risk for delirium.

JA Hiroshima General Hospital, Critical Care Medicine, Hatsukaichi, Japan
Published: 1 October 2015

\section{Reference}

1. Pandharipande PP, Pun BT, Herr DL, et al: Effect of sedation with dexmedetomidine vs lorazepam on acute brain dysfunction in mechanically ventilated patients: the MENDS randomized controlled trial. JAMA 2007, 298:2644-53.

doi:10.1186/2197-425X-3-S1-A332

Cite this article as: Sakuraya et al.: Additional sedative drugs to light sedation with dexmedetomidine is risk for delirium. Intensive Care Medicine Experimental 2015 3(Suppl 1):A332.
Submit your manuscript to a SpringerOpen ${ }^{\circ}$ journal and benefit from:

- Convenient online submission

- Rigorous peer review

- Immediate publication on acceptance

- Open access: articles freely available online

- High visibility within the field

- Retaining the copyright to your article
SpringerOpen $^{\odot}$

(c) 2015 Sakuraya et al.; This is an Open Access article distributed under the terms of the Creative Commons Attribution License (http:// creativecommons.org/licenses/by/4.0), which permits unrestricted use, distribution, and reproduction in any medium, provided the original work is properly cited. 